\title{
Profiles in practice: Stories of paleontology within an online, scientific community
}

The Community of Practice theoretical framework has been used theoretically and empirically to describe the diverse ways people learn from one another through social interaction in a variety of specific contexts. To date, most research of this genre has favored investigating the community and domain constructs of the theory over the authentic practice construct. Those interested in recognizing and supporting science learning in non-school contexts across a lifespan are then limited in efforts to delineate how communities engage in domain-specific practice. This is especially relevant in the study of online environments which afford more democratic forms of participation. With the goal of adding to both theoretical and practical knowledge, this study explored practices that members enacted on a community-based website specific to the domain of paleontology. We used a multiple case study approach to provide comparative and contrasting narratives concerning the development of practice within an online, scientific community. Methods consisted of downloading data from the website, including members' self-described attributes within member profiles, followed by their contributions to three of the website's features: the forums, activity feed, and messages. An analytical framework which typified members based on their self-described attributes was applied, then members' contributions were coded using an empiricallybased Communities of Practice framework. For one of the first times, we identified practice within an online, scientific community through comparing the contributions of three community members, finding that practice consisted of providing social support to other community members and having domain-based conversations.

Keywords: case study; community of practice; informal education; qualitative research 


\section{Introduction}

Online methods of communication are a staple of the modern world, necessitating characterization of the people and practices they enact within online environments. Within such online methods of communication, anyone has the capacity to participate in and contribute to conversations (Daume \& Galaz, 2016). From a social learning perspective, participation and contribution are recognized forms of learning (Wenger, White, \& Smith, 2009). In online spaces, especially those involving social media, democratic communication is especially noticeable in fields that are traditionally considered restricted, such as scientific disciplines including ecology and paleontology (Bex, Lundgren, \& Crippen, 2019). In these spaces, people from various levels of expertise are communicating about, participating in, and contributing to scientific work (Brossard \& Scheufele, 2013). While the literature is clear regarding learning outcomes (Land-Zandstra, Devilee, Snik, Buurmeijer, \& van den Broek, 2016; Vitone et al., 2016) and motivations (Raddick et al., 2010, 2013) of citizen science projects that include all members of society, limited evidence exists that describes the practice of people within digital spaces. Thus, within online environments, there is a dearth of understanding regarding how science is practiced along a continuum or how proficiency develops over time in interest-driven learning pursuits.

To understand how people from diverse backgrounds learn from one another regarding scientific issues, we must address the ways that people communicate, the specific practices they use and develop, and the ways that these stories coalesce within a scientific discipline. Paleontology has been recognized as a gateway science in that it can act as an entry point for learning regardless of age, experience, or expertise (Moran, McLaughlin, MacFadden, Jacobbe, \& Poole, 2015). This discipline also has a rich collaborative history among diverse entities, including museums, amateur paleontologists (i.e. citizen scientists), and professionals that use numerous digital platforms and media to enact their shared interest 
and work (Crippen et al., 2016). Thus, the science of paleontology offers the potential to examine scientific practices as evidence for learning within an online environment.

This was a comparative case study (Creswell, 2009) of the scientific practices exhibited by three individuals who identified differently within the domain: a paleontologist (i.e. a scientist), an amateur paleontologist, and a person interested in education and outreach. The research question that framed this study was: What forms of social paleontological practice occur within an online community and how are these forms related to the attributes of community members? Next, we describe the theoretical framework for considering online communication as evidence of scientific practice among a community of learners through the process of social learning. Then, we chronicle conversations of three online community members and the scientific practice that is illustrated.

\section{Theoretical Framework}

We approach this research from the perspective of Communities of Practice (CoP) (Wenger \& Synder, 2000; Wenger, 2000). Within a CoP, people coalesce around a topic of interest and enact behaviors specific to the topic. This perspective emerged from work describing the ways in which apprenticeships affect tradespeople (Lave \& Wenger, 1991). A widely-accepted theoretical description of CoPs emerged in the early 2000s and was comprised of three components: domain, community, and practice (Wenger, McDermott, \& Snyder, 2002). The domain defines the area of interest that united people, such as paleontology. The community, or people, are those who have an interest in the domain and communicate about it in some regard, whereas the practice is the ways in which they do this. In most research that employs the CoP framework, practice is the least defined element (Smith, Hayes, \& Shea, 2017), suggesting that this construct has been loosely interpreted, while the other elements of community and domain are much more clearly defined and 
interpreted, due to being at the forefront of empirically-based research.

Such empirical works that focus on community are found regardless of educational discipline, from studies of elementary classrooms (González-Howard \& McNeill, 2016), middle and high school classrooms (Forbes \& Skamp, 2013, 2014, 2016), and higher education contexts (Bondy, Beck, Curcio, \& Schroeder, 2017). Outside of formal education, CoPs have been used as a theoretical framework for understanding how people learn in museums (Kisiel, 2009) and how groups emerge in online learning environments (Liberatore, Bowkett, MacLeod, Spurr, \& Longnecker, 2018). In most of these studies, the focus is on a single interpretation of CoPs, that of building community via describing mutual engagement, joint enterprise, and a shared repertoire (Kimble, Hildreth, \& Bourdon, 2008a, 2008b; Wenger-Trayner, Fenton-O’Creevy, Hutchinson, Kubiak, \& Wenger-Trayner, 2015), which is different from focusing on how knowledge within the domain can be created by the community. Indeed, within these lines of research, researchers imply that if you build mechanisms for community, the knowledge follows.

Researchers who focus on communal aspects of the $\mathrm{CoP}$ framework tend to explicate community member divisions. For example, Dowthwaite and Sprinks (2019), dichotomously portray members, with scientists and the public characterized in stark contrast to one another. Other studies have attempted to classify amateur scientists by categorizing their motivations for participation (Corin, Jones, Andre, Childers, \& Stevens, 2015; Jones, Andre, Childers, \& Corin, 2014). Previous works concerning online community members have also described members dichotomously, with amateur paleontologists and professional paleontologists as contrasting groups, where status as an amateur paleontologist entailed membership in a fossil club or society whereas status as a professional paleontologist necessitated employment as a paleontologist (Crippen et al., 2016). However, these interpretations were somewhat limited, as those who sought to incorporate paleontology within their educational work, such as 
teachers and museum educators, or those people who sold and bought fossils for commercial purposes, were excluded or not considered. Our research emphasizes the development of practices that lead to legitimate participation in and contribution to the domain, which can allow researchers to establish for whom and under what conditions CoPs meet success.

Practice is a construct framed by Wenger, McDermott, and Snyder (2002) as 'a set of socially defined ways of doing things in a specific domain' (p. 38). Gray (2004), who described an online community of adult learning coordinators, explicates this through indicating that practices helped facilitate social community and develop proficiency. Sadler (2009) furthers this description within a formal learning environment, describing practice in science classrooms as a way for students to gain proficiency. Undergraduate education has been used as a proxy for developing proficiency in a domain (Alexander, 2003). These descriptions indicate that practice can act as a learning activity.

Within paleontology, proficiency is gained via participation in and contribution to the science. To show their proficiency, paleontologists construct an understanding of the past through participating in fieldwork and lab work as well as communication of hypotheses via oral and written presentations (Yacobucci \& Lockwood, 2012). In many ways, these practices can be ported into digital environments, acting as a basis for digital, social paleontology (Cunningham, Rahman, Lautenschlager, Rayfield, \& Donoghue, 2014; Lautenschlager \& Rücklin, 2014).

\section{Methodology}

\section{Context}

The context of this study was myFOSSIL, an online community designed to unite paleontologists from across the continuum of scientific experience and expertise in the study of paleontology. Paleontology was delimited as 'understanding the natural world through the collection, preparation, curation, and study of fossils' (Crippen et al., 2016). The site offered 
unique affordances, namely the possibility of studying an authentic scientific practice (i.e. paleontology) within an established community from multiple perspectives as well as the ability of researchers to collect a wide variety of digital data as members consented to participating when they signed up for the website.

Within this online community, members had the ability to create profiles, upload photographs of fossil specimens, communicate via the site's activity feed (similar to a Facebook wall), discuss paleontology-specific topics on forums, exchange private messages, and follow the activity of specific people by recognizing them as a friend (i.e. contact) (Figure 1). Starting in 2015, anyone interested in paleontology could view the site's content, however, participating in certain activities, such as posting in the forums and uploading fossil specimen photos, was limited to those who were members. Membership entailed filling out an intake survey about past experiences with paleontology and included an informed consent document before creating a member profile. As reported on the intake survey and verified with analytics, members discovered the site in a variety of ways, including searching the Internet for paleontology-specific content, finding the site from social media posts or word of mouth. During the timeframe of the study (October 2015-2017), the website included 822 members who had consented to participate. In this research, we include descriptions of three of those members who were chosen through maximal variation sampling (Creswell, 2009) to provide contextually-rich accounts of the ways in which paleontological practice was enacted in this digital, social environment. Additionally, we focus on three distinct members of the community to further interrogate Wenger, McDermott, and Snyder's (2002) supposition that members join, participate in, and contribute to a $\mathrm{CoP}$ in order to explore different $\mathrm{CoP}$ elements. Wenger and colleagues (2002) posit that some members care deeply about the domain, others are looking for community support, while others want to understand the practices within a particular domain. By describing three members from different 
backgrounds, with individual interests and expertise, our research examines the ways that full participation and element exploration can be experienced by members of diverse backgrounds.

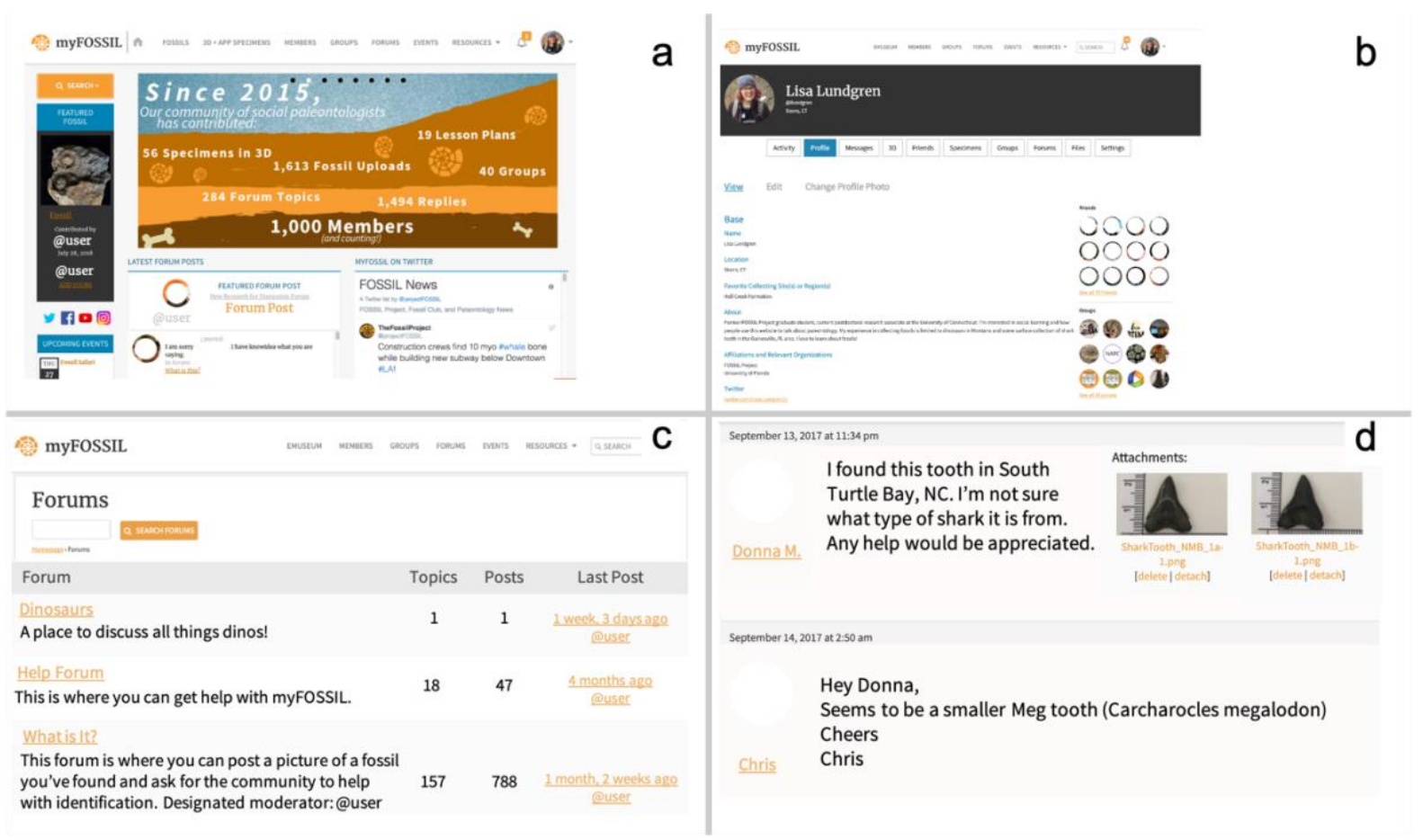

Figure 1. myFOSSIL website components.

a. The myFOSSIL homepage, where users were able to click through to specific website elements (e.g. Fossils, Forums, Events), see their notifications, update their profile, see most current forum posts, announcements, and fossils added.

b. User profile on myFOSSIL for the first author. User biographies like these were filled out by members and were examined by researchers to characterize participants using the Paleontological Identity Taxonomy.

c. The myFOSSIL forums, with descriptions of selected forums, with topics, posts, and most recent post in each forum displayed.

d. Example of an exchange within a forum concerning fossilized shark teeth.

\section{Method}

We collected data primarily through aggregating all intake survey data and data from forums, the activity feed, and messages that members created. Through their activity on and communication within these features, members expressed different practices and specific interests. For example, forums were divided into different topics, such as digitization of fossil specimens, 3D printing, and specific fossils or localities. We assumed that people participated 
in and contributed to forums that were within their areas of interest (Wenger et al., 2002). Data from the three features were exported as .csv files, converted to text, then coded and analyzed for themes using the computer-aided qualitative analysis software HyperRESEARCH (v. 3.0.2). The next sections will focus on in-depth descriptions of the two-pronged analytical framework for data collection and analysis.

A multiple case study design (Stake, 1995) was used for collecting and analyzing this study's qualitative data. Individual participants who were members of the community served as the cases, which were bounded by membership and interaction within the online community and were developed based upon a classification for how they identified with the domain. While the site included 822 members at the time of the study, 263 of these members qualified for further analysis, meeting the minimum criterion of contributing at least one piece of data (i.e. wrote a message, forum post, or posted on the activity feed) during the study's time period. This inclusion criterion was chosen as the ways in which members who did not contribute any data (i.e. 559 members) could not be parsed or analysed; these members can be described as "lurkers," who may stand to benefit from participating in an online community, but whose participation is difficult to account for (Sun, Rau, \& Ma, 2014).

Case selection was based on maximal variation sampling (Creswell, 2009) using the Paleontological Identity Taxonomy (PIT) (Lundgren, Crippen, \& Bex, 2018; Bex et al., 2019). In previous studies, the PIT has been shown to be a valid and reliable method for characterizing the diverse members of a paleontology community based upon how they describe themselves in relation to the domain, which is recognized as a representation of practice-based expertise. In short, members were classified based on a hierarchical taxonomy, starting with structure, which was a coarse-grain classification of members (i.e. individual, organization, club/group), then moved to a finer-grained one with the classification scheme of category (i.e. scientist, public, commercial, education \& outreach), followed by the finest 
grain of classification, consisting of 25 types (e.g. museum educator, amateur paleontologist), to describe a member's identity within the CoP. To determine such PIT classification of online community members, three researchers examined surveys filled out by users interested in becoming members of the site.

This classification of online community members with the PIT highlighted the potential for multiple cases (Table 1). With the descriptions provided by the PIT, we found that the structural level did not provide enough variation, as all members were classified as individuals ( $\mathrm{n}=263)$, and classification at the type-level parsed members too narrowly, which eliminated the possibility of comparisons across cases. Therefore, the middle tier of the PIT, the categorical level, was used for case selection. All four categories were present, although there were few commercial members $(n=5)$, who were excluded from analysis due to low numbers and low site activity. Membership included higher numbers of scientists $(\mathrm{n}=$ 44) and education and outreach members $(n=62)$, while members classified as public made up the majority $(\mathrm{n}=151)$. Cases from these three categories were selected via examining the amount of data they contributed within the study period, as researchers wanted to be able to describe themes using as much data as possible while staying true to the qualitative research paradigm of providing a thick, rich description of the context (Merriam, 2009). Then, members whose contributions were consistent with a quantitative analysis of the most frequently coded practices were chosen as cases of social paleontological practice. These cases were analyzed to determine members' similarities and differences in their enactment of practice within the online community.

Table 1. Cases selected via classification of online community members.

\begin{tabular}{lllll}
\hline Case & $\begin{array}{l}\text { PIT } \\
\text { structure }\end{array}$ & $\begin{array}{l}\text { PIT } \\
\text { category }\end{array}$ & PIT type & Additional Attributes \\
\hline Chris & Individual & Scientist & Paleontology & Age: 35-44
\end{tabular}




\begin{tabular}{|c|c|c|c|c|}
\hline & & & & $\begin{array}{l}\text { Interested in marine } \\
\text { vertebrate paleontology and } \\
\text { paleobotany }\end{array}$ \\
\hline \multirow[t]{2}{*}{ Ron } & Individual & Public & Amateur & Age: $65+$ \\
\hline & & & Paleontologist & $\begin{array}{l}\text { Interested in invertebrate } \\
\text { fossils and photography }\end{array}$ \\
\hline \multirow[t]{2}{*}{ April } & Individual & Education \& & Museum Educator & Age $35-44$ \\
\hline & & Outreach & & $\begin{array}{l}\text { Interested in paleontology in } \\
\text { classrooms }\end{array}$ \\
\hline
\end{tabular}

Following case selection, data were analyzed at two levels: within each case and then across the cases (Stake, 1995). Analysis involved using a framework for practice expressed as communication that pertained to the domain; details on this are provided in the following section. Then, all cases were analyzed for the same themes to show the extent to which the identified attributes of community members related to practice-development. This analysis approach allowed for the practices that were used in members' exchanges to be categorized.

Practice expressed as communication. To delineate practice, the authors turned to a conceptual framework for CoPs in digital habitats (Wenger et al., 2009). Within this framework, seven higher-level categories of learning activities were depicted, with specific activities nested in each category. Such higher-level learning activity were: Exchanges, Productive Inquiries, Building Shared Understanding, Producing Assets, Creating Standards, Having Formal Access to Knowledge, and Visits. As an example of the nested categorization, within the category of Exchanges, community members could enact the specific learning activities of news, information, pointers to resources, stories, tips, and document sharing. Aside from giving name to the higher-level categories and specific learning activities, Wenger et al. (2009) left them undefined. Within the online community of myFOSSIL, paleontological practices (i.e. higher-level categories and specific learning activities) took the form of chains of observable behavior that members enacted (Wenger et al., 2009), leaving digital traces, such as public forum and activity posts as well as private message threads. 
For this study, we iteratively operationalized the CoP framework from Wenger et al. (2009), focusing on practice. We interpreted the data through iterative coding sessions, discussion of codes amongst the research team, and the use of interrater reliability measures. Thus, what emerged was the Empirical Communities of Practice (ECoP) analytical framework, an interpretation as to what practices were evident on myFOSSIL (Table 2). 
Table 2. EcoP analytical framework of domain-specific learning activities and practices. Learning Activity Categories and Specific learning activities (practices) based on the CoP conceptual framework found in Wenger et al. (2009)

\begin{tabular}{|c|c|c|}
\hline $\begin{array}{l}\text { Learning Activity } \\
\text { Category }\end{array}$ & $\begin{array}{l}\text { Specific learning activity } \\
\text { (Practice) }\end{array}$ & Operational definition within myFOSSIL \\
\hline \multirow[t]{4}{*}{ Exchange } & News \& Information & $\begin{array}{l}\text { Story about paleontology presented for a lay audience or a general resource for paleontology, such as a geologic map or } \\
\text { dissemination of recent organization activity, links to blogs }\end{array}$ \\
\hline & $\begin{array}{l}\text { Pointers to Resources } \\
\text { Document Sharing }\end{array}$ & $\begin{array}{l}\text { Distribution of PDFs, PowerPoint presentations, journal articles or other domain-related materials to the CoP; reposting or } \\
\text { shifting location of posts on the website }\end{array}$ \\
\hline & Stories & Person-centered account of social paleontological practice \\
\hline & Tips & Members providing advice or best practice information to other member/s concerning social paleontology \\
\hline Productive Inquiries & Exploring Ideas & Brainstorming about the domain, not necessarily seeking answers \\
\hline $\begin{array}{l}\text { Building Shared } \\
\text { Understanding }\end{array}$ & Joint Events & Creation of meetups, conferences, or other such events that support all member classifications \\
\hline \multirow[t]{6}{*}{ Producing Assets } & Problem Solving & Communication concerning solutions related to the domain \\
\hline & Collaboration & Swapping of resources or information to create domain-specific partnerships \\
\hline & Boundary Crossing & Individuals demonstrating activities that are not consistent with their PIT categorization \\
\hline & Documenting Practice & Creation of digital artifacts that highlight real world experiences or ways to participate in and contribute to social paleontology \\
\hline & Learning Projects & Undefined \\
\hline & Collection & Undefined \\
\hline \multirow[t]{2}{*}{ Creating Standards } & Models of Practice & Members taking an authoritative stance when describing the practices within social paleontology \\
\hline & External Benchmarks & Information concerning best practices of digitization of specimens \\
\hline \multirow[t]{2}{*}{$\begin{array}{l}\text { Formal Access of } \\
\text { Knowledge }\end{array}$} & $\begin{array}{l}\text { Formal Practice Transfer; } \\
\text { Trainings; Workshops and } \\
\text { Invited Speakers }\end{array}$ & $\begin{array}{l}\text { Presentations, conference papers, or webinars that provide access to some aspect of the practice that were created by the member } \\
\text { of the CoP who is sharing them }\end{array}$ \\
\hline & Help Desk & Inquiring about domain-related topics - most often, the identification of specimens \\
\hline
\end{tabular}


Learning Activity

Category

Ungrouped Specific learning activity

(Practice)

Support

Field Trip Planning
Operational definition within myFOSSIL

Members thanking others for contributing, acknowledging a contribution or being otherwise social without adding to knowledge per se

Discussion of events that relate to domain-specific outings 
The unit of data analysis ranged from singular sentences to full paragraphs written by members. For interrater reliability measures, the first author coded all the data over a month's period, then the third author re-coded 10 percent of the data at a later date. With this process, interrater reliability was conducted for each website feature (forum posts, activity feed, and messages), with kappa values ranging from moderate to substantial levels of agreement (Table 3).

Table 3. Interrater Reliability for Features on myFOSSIL

\begin{tabular}{lccc}
\hline Digital Trace Data Type & $\mathrm{N}$ & $\mathrm{N}$ recoded & $\mathrm{k}$ (level of agreement) \\
\hline Forum Posts & 1950 & 195 & $\mathrm{k}=.57$ (moderate) \\
Activity Posts & 1297 & 129 & $\mathrm{k}=.70$ (substantial) \\
Messages & 848 & 84 & $\mathrm{k}=.61$ (moderate) \\
\hline
\end{tabular}

\section{Results}

We focus next on case descriptions of three members. These members will be described via their classification (i.e. scientist, public, or education and outreach). We describe the paleontological practices they most often enacted on the site to answer how such practices relate to the attributes of selected members of an online, scientific community. Member names and their paleontological expertise/interests have been modified to protect identities.

\section{Scientist}

Chris was an individual, representing only himself, who fit into the category of scientist, and the type of paleontology. Chris was between the ages of 35-44 and had been a member since the beta testing phase in 2014. Chris' main area of interest was digitization of 
fossil specimens. During the study period, he was a marine vertebrate paleontological researcher at a natural history museum affiliated with a large university in the United States.

Chris contributed activity feed posts, messages, and forum posts. He most often created forum posts $(n=140)$ and activity posts $(n=46)$, but rarely sent messages $(n=1)$. Chris most often used the following practices, as identified in the ECoP, across his contributions: Support $(n=51)$, Tips $(n=30)$, and Problem Solving $(n=25)$. An overall description of Chris is that he was a social supporter who sought to solve domain-specific problems.

Chris most often offered Support to his fellow members, either by thanking them for contributing or was social without adding knowledge about the domain per se $(n=51)$. In one instance, Chris created a tutorial for cleaning and curating fossils. A public member indicated that the tutorial was helpful, so Chris responded, 'Thank you so much for your feedback, I really appreciate it and feel very pleased. That is just the right reward for all that work. Once again: Thank you very much!' (Chris, scientist, forum post ID \# 3424). With this forum post, Chris exemplifies the notion of Support, indicating his gratitude in regard to feedback. This kind of response is not domain-specific, but still important for a digital CoP which sought to build community and develop scientific knowledge: it acknowledged the response of one member, which helped to build community as individual member input was recognized.

Chris also provided many Tips $(\mathrm{n}=30)$, which supplied other members with advice or best practice information. For example, in one post concerning specimen preparation, Chris indicated a technique that he used then advised, 'I forgot to mention that you should not look into the bright white flame... but I'm sure you already know that' (Chris, scientist, forum post ID \# 2267). With this post, Chris explicitly provided other members with domain-specific advice. When he provided this advice, he was responding to a forum post that was started by a public member (Ron). When Chris indicated in his post that Ron 'already [knew] that,' the 
playful, teasing tone indicated a familiarity with the other member, showing the ability to provide advice while being friendly. Ron replied in the forum, addressing Chris' technique suggestion, indicating that he was interested in trying it, but was concerned about damaging his specimens. Chris then added a video tutorial about his technique and Ron added photos of specimens to show how he was using (and not using!) the technique. This shows how Chris created forum posts that were coded as Tips, in which he rarely provided background information or explicit reasoning for his responses. Instead he provided answers, which, in some cases provided fodder for additional conversation, although it was akin to a dyad exchanging information versus a conversation amongst multiple community members.

Chris contributed many posts that were coded as Problem Solving $(n=25)$ in which he communicated with other members about solutions related to the domain. Chris often responded to other members concerning the practice of digitization, offering solutions. For instance, some members categorized as public posted in a forum, indicating their interest in using cell phone camera attachments to take photos. Chris created a forum post that described the differences in quality, focusing on price. However, he was also mindful of the barriers of purchasing high-priced equipment, indicating,

We have to think about that not everybody is able to spend that much money just for a lens. We invite everybody to be part of this community and as long as we can help to make the quality of images better even with not so expensive tools (Chris, scientist, forum post ID \#2620).

This quote highlights the way that Chris thought about the community. He applied his expertise in photography while considering the ways in which other community members could contribute. In response, other members replied, showing their cell phone camera attachments, adding pictures to indicate the tool's quality. This shows how Chris' answers, coded as Problem Solving, added to other members' practice. These solutions related to the domain of paleontology allowed for additional community members to contribute to the 
domain through the digitization of fossil specimens. Additionally, Chris' solutions were domain-specific and thus related to his identity as a paleontologist: Chris cared deeply about the domain of paleontology, and sought to encourage others to care about it too, which is one way that Wenger and colleagues (2002) describe an avenue towards full participation in a CoP.

Public

Ron was an individual who was classified as public at the category level, and as an amateur paleontologist at the type level. He was a member of a fossil club that was based in the United States and joined the site as a beta tester. Ron was retired, over 65 years of age, and had an interest in invertebrate fossils and photography. Over the two-year period of the study, Ron contributed to all features of the website, including the forums ( $\mathrm{n}=121)$, the activity feed $(n=52)$, and messages $(n=13)$. Most often, Ron created posts that included the practices of Problem Solving $(n=45)$, Tips $(n=43)$, and Support $(n=30)$. An overall description was that he was a problem-solver and adviser whose focus was creating a digital record of real-world expertise.

Ron often sought to communicate about domain-specific solutions (i.e. Problem Solving) when posting on the site $(\mathrm{n}=45)$. In a forum about fossil preparation, Ron provided a detailed for cleaning fossils, focusing on a chemical that he knew some other members had used. Ron lamented that the chemical could not be found in the United States. Upon seeing this post, Chris, the scientist described previously, indicated that he would look into ways of obtaining the chemical outside of the United States. After a lengthy wait for Chris to respond, Ron created a forum post to spark the conversation, writing, 'I'm hoping Chris (@chris)will get back to us about [chemical] when he returns from his travels' (Ron, public, forum post ID \# 3001). While Ron tagged Chris to update members about the chemical, two other members 
(both categorized as public), added their experiences with the chemical, discussing specific dilutions that worked well and the tools they use to prepare fossil specimens.

In tagging Chris, Ron was attempting to solve a domain-specific problem, specifically that of finding a good chemical to clean fossils, but it also allowed other members to add the ways in which they solved domain-specific problems related to fossil preparation. Ron's contribution exemplifies the practice of Problem Solving, focusing on a domain-specific problem (e.g. finding a chemical used to prepare fossil specimens), and the role that he played as a public member on the site. He was able to speak knowledgeably about fossil preparation and curation techniques then communicate with others concerning those domainspecific problems, sparking conversations about those problems by tagging others and following up with additional information; by communicating in such a manner Ron's identity as a knowledgeable member of the public relates directly to Wenger and colleagues' (2002) description of members joining, participating in, and contributing to CoPs to help others to understand domain-based practices.

Ron further indicated his expertise in regard to fieldwork, identification, and curation in his responses that were coded as Tips $(n=43)$. In these posts, Ron gave identification information that promoted knowledge of specimens. Ron gave Tips to members of any classification. For instance, one scientist within the community posted a photo of a fossil specimen that was found by a member who was categorized as a member of the public. In her post, the scientist also tagged Ron, who had extensive experience with invertebrate fossils, asking for his identification help. Ron responded, writing, 'Orin, Ann, these are indeed [invertebrate fossil]. [Redacted] is the most commonly found [invertebrate fossil] in this area. Orin you might consider joining First Fossil Club if you are collecting in this area. We have a member who is an expert on [invertebrate fossils] and can help identify your specimens' (Ron, public, forum post ID \# 2266). Neither the scientist nor member of the public 
responded to Ron, however a different scientist added to the conversation, using the practice of Support to thank the member of the public for posting. His expertise level was acknowledged by those who tagged him in posts related to his interests which included invertebrate fossils, fossil preparation, and curation techniques. This shows how a member of the public (i.e. Ron) added to scientific practice within the community, enhancing a social learning experience, facilitating connections that may not have occurred without the online community's affordances.

In addition to providing domain-specific expertise, Ron was also very responsive to his fellow site members, often providing critical feedback followed by messages of Support $(\mathrm{n}=30)$. Whenever another member followed up with Ron indicating that they gained something from their interaction with him, whether it was an identification, curation technique feedback, or specimen information corrections, Ron quickly followed up, writing responses like 'Glad I could help' (Ron, public, activity post ID \# 5764), 'No problem, you're welcome!' (Ron, public, activity post ID \# 16931), and 'We're always willing to communicate with others about the great Paleozoic materials!' (Ron, public, activity post ID \# 2108). These posts highlight Ron's responsiveness to other members, regardless of their classification, as well as his role in the community. Aside from being a prolific content creator, he was also interested in community development, which entailed an available and good-natured demeanor as evidenced by his posts coded as Support.

In summary, Ron was acting as a representation of the category of public when he posted data that included the practices of Problem Solving, Tips, and Support. Ron's contributions demonstrate how a member enacted paleontological practices including solving domain-specific problems, caring about the community, and helping share information with others to aid in creation of an online, scientific CoP.

\section{Education and Outreach}


April was classified as education and outreach at the category level, and as museum educator at the type level. April, who was between the ages of 35-44, was affiliated with a museum on a university campus. April was interested in integrating photogrammetry techniques and paleontological concepts in classrooms. She joined the site as a beta tester. April contributed to the activity feed $(n=49)$, forums $(n=36)$ and messages $(n=2)$. She most often contributed posts about News and Information $(n=15)$ and Pointers to Resources $(\mathrm{n}=12)$. As an education and outreach member, April was interested in social- and researchspecific dissemination of information, while seeking social- and research-specific support.

April mostly created activity posts or made forum posts regarding integrating paleontology with education, regardless of grade level; these were coded as News and Information posts $(\mathrm{n}=15)$ as they were stories about paleontology presented for a lay audience, dissemination of recent organization activity, or links to blogs. Through these posts, April indicated that she read blogs about paleontology and graduate education. For example, April wrote, 'Hi all, I thought you would like to read this regarding impact factor: (hyperlink to article)' (April, education and outreach, activity post ID \# 51). Despite April providing many links to such blogs, her posts often failed to engender conversations about these topics. This might mean that members interacted with these posts (i.e. by clicking on the hyperlink), but they did not discuss the content of the posts explicitly on the website. If considered as a way for conversations to start in an online environment, these types of posts were ineffective. She also disseminated information from projects that she worked with, such as distributing pictures, writing, 'hello wonderful [redacted] group members. Here's a picture of all of us :)' (April, education and outreach, activity post ID \# 17345). Education and outreach members, like April, often sought to use the site to connect to one another through the inclusion of domain-specific topics, although these posts were not always centered on scientific practice, instead, they featured the sharing of events that education and outreach 
members participated in. These news and information posts rarely generated interaction, which could mean that these practice-based posts are not useful for facilitating learning in an online environment. However, it could be argued that her contributions supported the building of community, and creating a supportive community, which is an avenue towards full participation in a $\mathrm{CoP}$.

Sometimes, education and outreach members shared Pointers to Resources; April was no different $(\mathrm{n}=12)$. These posts linked to research articles, PowerPoint presentations, or other domain-related materials. Specifically, April often posted links that clarified or added to domain-related experiences she had. For example, she attended a webinar, then posted a link to it, writing,

Hey guys, here's a recording of the NSF webinar Mark and I attended yesterday. It was more about the introduction of a journal that looks for papers bridging the gap between informal and formal STEM education. Perhaps this is a good venue for the paper about [redacted]. Here's the link to the recording: (link) (April, education and outreach, activity post ID \# 13122).

With this activity post, April shared a resource that others could use, namely, a link to a webinar clarifying the scope of a new journal, which could be of benefit to the community. In other instances, April willingly provided resources to others that would be of interest to members who cared about paleontology education and outreach. Resource sharing relates to April's member status of education and outreach: she sought to disseminate research-specific information to other members, perhaps at the expense of enacting other forms of practice.

\section{Comparing Profiles in Practice}

The interactions by these members on the site have similarities and differences that allow for understanding the forms of practice-development within social paleontology, which 
can explicate the ways that social learning occurs in online environments. Following the procedure for multiple case studies, the next section will describe the cross-case comparisons.

In comparing the ways that Chris (the scientist) and Ron (the public member) interacted on the site, patterns emerge in which both used the same practices, yet these members approached the practices in distinct ways. Both Chris and Ron often sought to solve problems related to the domain of paleontology. Chris valued contextualization, while Ron valued others' definitions. They often traded forum posts rapidly, responding to one another and other members within a day or two. An example of this is a forum topic in which one public member asked about the difference between three types of fossils: molds, casts, and steinkerns. The member who created this post tagged both Chris and Ron, asking for their thoughts on the matter. Three scientists responded with their interpretations of what molds, casts, and steinkerns were, as did Ron and Chris. A lengthy discussion about semantics followed, with Ron and the original poster rapidly replying to one another, adding their own viewpoints and experiences with collecting, curating, and digitizing these types of fossils. Finally, Ron wrote that the member who created the post originally was 'over complicating this' by attempting 'to improve these definitions. The definitions of molds and casts were made very simply at the beginning of this thread and that's all you really need' (Ron, public, forum post ID \# 3745). Chris then indicated that the solution was to 'decide from a contextual basis' (Chris, scientist, forum post ID \# 3694). Both of these responses were coded as Problem Solving, as members were communicating about solutions related to the domain. Ron's solution was to refer to information found earlier in the forum post thread; Chris' was to make inferences on a case-by-case basis. These approaches to problem solving seemed to emerge from different ways of viewing the world, which could have been tied to each member's PIT category. This relates to STEM learning in that domain-specific practices were 
explicated within this online environment with people from across the continuum of expertise contributing viewpoints based on their experience.

While some differences in approaches were seen, in many ways Chris and Ron developed their practice in similar manners. Both Ron and Chris provided other members with Tips, or advice or best practice information in a similar way, especially in terms of things they were interested in. Ron was especially interested in curating fossils whereas Chris was focused on photography. Ron specifically asked for a forum to be created that centered on curating fossils, then wrote extensively about the ways that he curated his fossils. The Tips that he provided included phrases such as, 'so, when thinking of your own curation system, consider what kind of disaster could make your system fail and your specimens become curiosities. Once you've done this you can modify your system to compensate' (Ron, public, forum post ID \# 11467). By comparison, Chris offered photography tips, 'Would you like to get images with a camera?...the easiest way is to buy a regular camera tripod. You can get some... for around $\$ 10 \ldots$ [this] makes it much easier to get blur free images.' (Chris, scientist, forum post ID \# 2049). In both these forum posts, each member offered information to other members to ensure good experiences with social paleontology. This information could enhance trust within a community, which in turn can lead to more members participating and contributing to the social learning experience.

April created the majority of her forum posts within the forums that were centered on photogrammetry and paleontology education. Sometimes, April would give other members Tips about her interests. One example occurred when April described numerous reasons why a photogrammetry could go awry (April, education and outreach, forum post ID \# 4295). Aside from the interest-based differences, the formulation of April's posts differed from Ron and Chris. April's formulation of Tips were seemingly self-focused, with multiple references to her expertise and experiences. In contrast, although Ron and Chris had extensive 
experience and expertise, they framed their Tips towards an audience, indicating others could follow their lead.

In summary, Ron and Chris, the public member and the scientist, both used practices in a different way than April, the education and outreach member. April sought to use the site to disseminate information; Ron and Chris utilized the site to solve problems.

\section{Discussion}

CoPs have been touted as being both an easily-employable strategy for building relationships between people (Wenger et al., 2009) as well as being a well-defined and sound theory for understanding social learning processes (Wenger, 2000). Despite these proclamations, there has been limited evidence to support these claims, especially when online, science, domain-specific CoPs are examined. Thus, we sought to answer questions related to practice-development of community members in an online science community. In this section, we contextualize our findings, describing the ways that people and practice within the online community of myFOSSIL can inform theory and practice in the design and development of online communities for informal science learning.

In the domain of paleontology, scientific work has been centered on the practices of collection, identification, preparation, and curation of fossils (Crippen et al., 2016). While each of these is integral to paleontology as it is experienced in the real world, there has been a shift towards the digital world, especially the ways in which people contribute to paleontological knowledge generation in online environments. The results from this study explicate the integration of real-world knowledge generation in paleontology with the development of people's practices within an online environment. Within online environments, practice has been defined in terms of knowledge exchange (Pan et al., 2015) or in terms of social media interactions (Liberatore et al., 2018) with CoP members writing, discussing, and commenting to one another. While these high-level depictions of practice are 
useful, they fall short as they do not classify nor clarify the specific ways in which CoP members contribute. On myFOSSIL, we used a multiple case study approach to delve the ways that community members enacted practice.

Ron and Chris, the described public and scientist members, enacted practice in similar ways, which has implications for the ways that identity and expertise can augment learning within informal, online spaces. Recent studies (Dowthwaite \& Sprinks, 2019; Krzywosynska, 2019; Sharma \& Land, 2018) have focused on the identity of members within online scientific communities, indicating that people from across the continuum of expertise affect each others' practices. Although these studies approached identity within disparate domains (i.e. citizen science, soil science, and diabetes), they determined that the identities of community members allowed for various perspectives which in turn allowed scientific practice to flourish. Within the current study, members used their identity-based expertises to build community within the domain of paleontology while enacting scientific practice. Furthermore, comparing and contrasting three members with distinct identities allowed us to further interrogate how Wenger and colleagues (2002) describe member exploration of different CoP elements (i.e. community, practice, and domain). Ron and Chris were interested in the domain of paleontology; Chris sought to teach others about particular domain-specific practices; and April looked for the support of the community as she disseminated information. These three, specific identity-based explorations of a paleontology-specific CoP allow a richer understanding of the theoretical suppositions that Wenger and colleagues lay out.

Additionally, the enactment of scientific practice within an online environment has implications for the field of science communication, specifically when considering the deficit model of science communication (Bucchi, 2008). Within this model, the gulf between scientists and an ignorant public is emphasized: scientists are guardians of scientific 
knowledge who pass their knowledge to members of the public, who are unable to obtain the knowledge themselves. myFOSSIL was created with the explicit aim of building a community of palaeontologists from across a continuum of expertise; if our research showed that members merely disseminated information without having conversations, it could be said that the site failed in its goal of creating a community who talks with one another about a domain instead of at one another. Within the current study, Chris, Ron, and April exchanged knowledge and contributed to the site in unique and meaningful ways. This implies that for the field of paleontology, the emphasis of science communication should not focus on the socalled ignorance of people who are not professional scientists, but rather, on how much they can add to paleontology as they have previous knowledge, experience, and expertise that can add to scientific understanding.

We see the issue of the deficit model of science communication as parallel to direct instructional models of teaching and learning, where teachers provide science content to passive students (Ryder, Burton, \& Silberg, 2006). Research has emphasized the ineffective and inauthentic nature of direct instruction in science education (Ryder, Burton, \& Silberg, 2006) as well as the issues with the deficit model of science communication (Bucchi, 2008). The findings of this study add evidence to claims that deficit models of communication and learning are outdated and ineffective as diverse members with varied expertise can learn from one another in meaningful ways within an online, scientific community.

April, the education and outreach member, focused on disseminating information important to her. Many of her contributions were coded as news and information, which, on social media platforms, has been shown to be an ineffective form of communicating to paleontological conversations (Bex et al., 2019). Forbes and Skamp's (2016, 2014, 2013) research on a collaborative initiative called MyScience provides insight into April's actions. MyScience focused on connecting scientists and teachers in a CoP to develop formal science 
education. Forbes and Skamp (2014) indicate that the teachers involved in MyScience 'viewed their role as providing support to students' as well as 'fostering students' interest and enthusiasm in science' (p. 22), which is similar to the ways that April, the education and outreach member on myFOSSIL, chose to contribute. By asking for social- and researchsupport, April was filling the same role that the teachers were in the study by Forbes and Skamp (2014). April's contributions and social learning is important to note in conjunction with Forbes and Skamp's prior work, which took place in face-to-face, formal classrooms. Our research shows that within online, scientific communities educators fill similar roles to the roles filled by educators in a face-to-face, formal learning environment. The current research provides some of the first evidence of this occurring, but further investigation into the notion that educators might seek out or contribute to online communities in a manner that is distinctive or separate from members who are not educators is needed.

\section{Conclusion}

Current research regarding people and the practices they enact within online scientific communities has been limited, describing the community as the focus, with a limited focus on practice (Smith, Hayes, \& Shea, 2017). With this work we sought to characterize the practices of three case studies of community members. In describing the practices of the three members, we found that Ron, a member of the public, and Chris, a scientist, conducted themselves in similar manners, seeking to solve domain-specific problems and offer social support to other members. In somewhat of a contrast, April, the education and outreach member, was more focused on disseminating information. These findings inform our understanding of the practices within online communities which, until this study, were broadly defined. Using rich descriptions and highlighting quotes from the members themselves, we showed the similarities and differences across members. This research can serve as a basis for those who wish to describe practice in other online communities. The 
implications for informal, digital science learning are that members of an online science community can learn through practice, providing social and scientific support to other members.

\section{References}

Alexander, P. A. (2003). The development of expertise: the journey from acclimation to proficiency. Educational Researcher, 32(8), 10-14. doi:10.3102/0013189X032008010

Bondy, E., Beck, B., Curcio, R., \& Schroeder, S. (2017). Dispositions for critical social justice teaching and learning. Journal of Critical Thought and Praxis, 6(3), Article 1.

Bex, R. T., II., Lundgren, L., \& Crippen, K. J. (2019). Scientific Twitter: The flow of paleontological communication across a social network. PLOS ONE, 14(7): e0219688. doi: 10.1371/journal. pone.0219688

Brossard, D., \& Scheufele, D. A. (2013). Science, new media, and the public. Science, $339(6115), 40-41$.

Bucchi, M. (2008). Of deficits, deviations and dialogues: Theories of public communication of science. In M. Bucchi \& B. Trench (Eds.), Handbook of public communication of science and technology (pp. 57-76). London, England: Routledge.

Corin, E. N., Jones, M. G., Andre, T., Childers, G. M., \& Stevens, V. (2015). Science hobbyists: Active users of the science-learning ecosystem. International Journal of Science Education, Part B, 1-20. doi:10.1080/21548455.2015.1118664

Creswell, J. (2009). Research Design: Qualitative, Quantitative, and Mixed Method Approaches. Thousand Oaks, CA: SAGE Publications, Inc.

Crippen, K. J., Ellis, S., Dunckel, B. A., Hendy, A. J. W., \& MacFadden, B. J. (2016). Seeking shared practice: A juxtaposition of the attributes and activities of organized fossil groups with those of professional paleontology. Journal of Science Education and Technology, 25(5), 731-746. https://doi.org/10.1007/s10956-016-9627-3

Cunningham, J. A., Rahman, I. A., Lautenschlager, S., Rayfield, E. J., \& Donoghue, P. C. J. (2014). A virtual world of paleontology. Trends in Ecology \& Evolution, 29(6), 347357. doi:10.1016/j.tree.2014.04.004

Daume, S., \& Galaz, V. (2016). 'Anyone know what species this is?' - Twitter conversations as embryonic Citizen Science communities. Plos One, 11(3), e0151387. doi:10.1371/journal.pone.0151387

Dowthwaite, L., \& Sprinks, J. (2019). Citizen science and the professional-amateur divide: lessons from differing online practices. Journal of Communication Management, 18(1). doi:10.22323/2.18010206

Forbes, A., \& Skamp, K. (2013). Knowing and learning about science in primary school 'Communities of Science Practice': The views of participating scientists in the MyScience initiative. Research in Science Education, 43(3), 1005-1028. doi:10.1007/s11165-012-9295-0

Forbes, A., \& Skamp, K. (2014). 'Because we weren't actually teaching them, we thought they weren't learning': Primary teacher perspectives from the MyScience initiative. Research in Science Education, 44(1), 1-25. doi:10.1007/s11165-013-9367-9

Forbes, A., \& Skamp, K. (2016). Secondary science teachers' and students' involvement in a primary school community of science practice: how it changed their practices and interest in science. Research in Science Education, 46(1), 91-112. doi:10.1007/s11165-014-9457-3 
González-Howard, M., \& McNeill, K. L. (2016). Learning in a community of practice: Factors impacting English-learning students' engagement in scientific argumentation. Journal of Research in Science Teaching, 53(4), 527-553. doi:10.1002/tea.21310

Gray, B. (2004). Informal learning in an online community of practice. Journal of Distance Education, 19(1), 20-35.

Jones, M. G., Andre, T., Childers, G., \& Corin, E. (2014). Where are the women and minority amateur paleontologists? A study of the development of characteristics of science hobbyists. Presented at the 10th North American Paleontological Convention.

Ke, Q., Ahn, Y.-Y., \& Sugimoto, C. R. (2017). A systematic identification and analysis of scientists on Twitter. Plos One, 12(4), e0175368. doi:10.1371/journal.pone.0175368

Kimble, C., Hildreth, P. M., \& Bourdon, I. (Eds.). (2008a). Communities of Practice: Creating learning environments for educators, Volume 1. Charlotte, NC: Information Age Publishing.

Kimble, C., Hildreth, P. M., \& Bourdon, I. (Eds.). (2008b). Communities of practice: Creating learning environments for educators, Volume 2. Charlotte, NC: Information Age Publishers, Inc.

Kisiel, J. F. (2009). Exploring a school-aquarium collaboration: An intersection of communities of practice. Science Education, 94(1), 95-121. doi:10.1002/sce.20350

Krzywoszynska, A. (2019). Making knowledge and meaning in communities of practice: What role may science play? The case of sustainable soil management in England. Soil Use and Management. doi: 10.1111/sum.12487

Land-Zandstra, A. M., Devilee, J. L. A., Snik, F., Buurmeijer, F., \& van den Broek, J. M. (2016). Citizen science on a smartphone: Participants' motivations and learning. Public Understanding of Science, 25(1), 45-60. doi:10.1177/0963662515602406

Lautenschlager, S., \& Rücklin, M. (2014). Beyond the print-virtual paleontology in science publishing, outreach, and education. Journal of Paleontology, 88(4), 727-734. doi:10.1666/13-085

Lave, J., \& Wenger, E. (1991). Situated learning. Cambridge, UK: Cambridge University Press.

Liberatore, A., Bowkett, E., MacLeod, C. J., Spurr, E., \& Longnecker, N. (2018). Social media as a platform for a citizen science community of practice. Citizen Science: Theory and Practice, 3(1). doi:10.5334/cstp.108

Lundgren, L., Crippen, K. J., \& Bex, R. T., II. (2018). Digging into the PIT: A new tool for characterizing the social paleontological community. In The Proceedings of E-Learn: World Conference on E-Learning in Corporate, Government, Healthcare, and Higher Education 2018, pp. 76-83. Chesapeake, VA: Association for the Advancement of Computing in Education (AACE).

Merriam, S. B. (2009). Qualitative research. San Francisco: Jossey-Bass.

Moran, S., McLaughlin, C., MacFadden, B., Jacobbe, E., \& Poole, M. (2015). Fossil explorers: Third-grade students' examine ancient organisms in modern times. Science and Children, 53(4), 62-67.

Pan, Y., Xu, Y., Wang, X., Zhang, C., Ling, H., \& Lin, J. (2015). Integrating social networking support for dyadic knowledge exchange: A study in a virtual community of practice. Information \& Management, 52(1), 61-70. doi:10.1016/j.im.2014.10.001

Raddick, M. J., Bracey, G., Gay, P. L., Lintott, C. J., Murray, P., Schawinski, K., ... Vandenberg, J. (2010). Galaxy Zoo: Exploring the motivations of citizen science volunteers. Astronomy Education Review, 9(1). doi:10.3847/AER2009036

Raddick, M. J., Bracey, G., Gay, P. L., Lintott, C. L., Cardamone, C., Murray, P., ... Vandenberg, J. (2013). Galaxy Zoo: Motivations of citizen scientists. Astronomy Education, 12. 
Ryder, R. J., Burton, J. L., \& Silberg, A. (2006). Longitudinal study of direct instruction effects from first through third grades. The Journal of Educational Research, 99(3), 179-192. https://doi.org/10.3200/JOER.99.3.179-192

Sadler, T. D. (2009). Situated learning in science education: socio-scientific issues as contexts for practice. Studies in Science Education, 45(1), 1-42. doi:10.1080/03057260802681839

Sharma, P., \& Land, S. (2018). Patterns of knowledge sharing in an online affinity space for diabetes. Educational Technology Research and Development, 67(2), 1-29. https://doi.org/10.1007/s11423-018-9609-7

Smith, S. U., Hayes, S., \& Shea, P. (2017). A Critical Review of the Use of Wenger's Community of Practice (CoP) Theoretical Framework in Online and Blended Learning Research, 2000-2014. Online Learning, 21(1). doi: 10.24059/olj.v21i1.963

Stake, R. E. (1995). The art of case study research. Thousand Oaks, CA: Sage Publications.

Sun, N., Rau, P. P.-L., \& Ma, L. (2014). Understanding lurkers in online communities: A literature review. Computers in Human Behavior, 38, 110-117. https://doi.org/10.1016/j.chb.2014.05.022

Vitone, T., Stofer, K., Steininger, M. S., Hulcr, J., Dunn, R., \& Lucky, A. (2016). School of Ants goes to college: Integrating citizen science into the general education classroom increases engagement with science. Journal of Science Communication, 15(1), A03.

Wenger, E. (2000). Communities of practice and social learning systems. Organization, 7(2), 225-246. doi:10.1177/135050840072002

Wenger, E., McDermott, R. A., \& Snyder, W. (2002). Cultivating communities of practice. Boston, Mass: Harvard Business School Press.

Wenger, E., \& Synder, W. (2000). Communities of practice: The organizational frontier. Harvard Business Review, 78(1), 4-20.

Wenger, E., White, N., \& Smith, J. D. (2009). Digital habitats: stewarding technology for communities. Portland, OR: CPsquare.

Wenger-Trayner, E., Fenton-O'Creevy, M., Hutchinson, S., Kubiak, C., \& Wenger-Trayner, B. (2015). Learning in landscapes of practice: Boundaries, identity, and knowledgeability in practice-based learning. London: Routledge.

Yacobucci, M. M., \& Lockwood, R. (2012). Teaching paleontology in the 21st Century. Ithaca, NY: Paleontological Research Institution. 